REPORT

\title{
Reconfiguring Auburn University's Main Library for Engaged Active Student Learning
}

September 20, 2016

Marcia Boosinger, Bonnie MacEwan, Denise Baker, Ashley Goerke, Adelia Grabowsky, Cory Latham, Kasia Leousis, Christopher Mixon, Catherine Price, Juliet Rumble, Greg Schmidt, Cayce Van Horn, Danielle Cooper, Lise McKean, Nancy Fried Foster

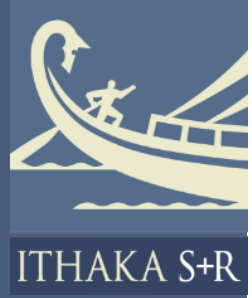




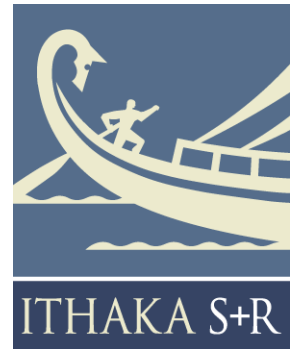

Ithaka $\mathrm{S}+\mathrm{R}$ is a strategic consulting and research service provided by ITHAKA, a not-for-profit organization dedicated to helping the academic community use digital technologies to preserve the scholarly record and to advance research and teaching in sustainable ways. Ithaka $\mathrm{S}+\mathrm{R}$ focuses on the transformation of scholarship and teaching in an online environment, with the goal of identifying the critical issues facing our community and acting as a catalyst for change. JSTOR, a research and learning platform, and Portico, a digital preservation service, are also part of ITHAKA.
Copyright 2016 ITHAKA. This work is licensed under a Creative Commons Attribution-NonCommercial 4.0 International License. To view a copy of the license, please see http://creativecommons.org/licenses/by-nc/4.0/.

ITHAKA is interested in disseminating this brief as widely as possible. Please contact us with any questions about using the report: research@ithaka.org. 


\section{Introduction}

The effects of technological innovation have been rapid, significant, and well documented, and libraries have responded to changes in the way people read, communicate, and do research by providing digital content and renovating buildings so that they support new, technology-enhanced ways of work.

But what about teaching and learning? More and more colleges and universities provide "hybrid" courses, "flipped" classrooms, and "active learning." Instructors put lecture material online and engage students in group exploration and problem solving during class time. Classrooms are changing to support new pedagogies: formal learning spaces with pods of desks and hookups to screens are now common on many campuses. IT and facilities organizations work toward providing ubiquitous power and connectivity. Instructional technologists and other specialists help with apps, devices, and the creation of online learning activities, assignments, videos, and documents. An Ithaka S+R case study describes an initiative at University of Technology Sydney (UTS) to shape spaces for new kinds of teaching and learning; a number of innovative buildings have gone up in the past few years on their urban Sydney campus to support new pedagogies, and students stay on campus to work in them far longer than before. ${ }^{1}$

In the face of changes in teaching and learning, academic libraries are responding with changes of their own. New pedagogies are creating opportunities for libraries to connect directly to the curriculum and support students who are being asked to work in new ways. It is one thing to recognize that change is needed, however, and another to design changes that will effectively support emerging ways of teaching and learning, especially when it is still early days in the change process. Such was the case at Auburn University, where a project to construct a new classroom building specifically for Engaged Active Student Learning (EASL) classes provided the library with an opportunity to renovate its main floor. The new Mell Classroom Building will incorporate in its entry atrium the library façade, and the library's third and fourth floors will connect to hallways in the new structure. Library leaders seized the opportunity to provide space specifically to support the out-of-class-time academic activities of students in EASL classes.

${ }^{1}$ Nancy Fried Foster and Christine Mulhern, "Making a Place for Curricular Transformation at the University of Technology Sydney," New York: Ithaka S+R, September 3, 2015, http://dx.doi.org/10.18665/sr.241927. 


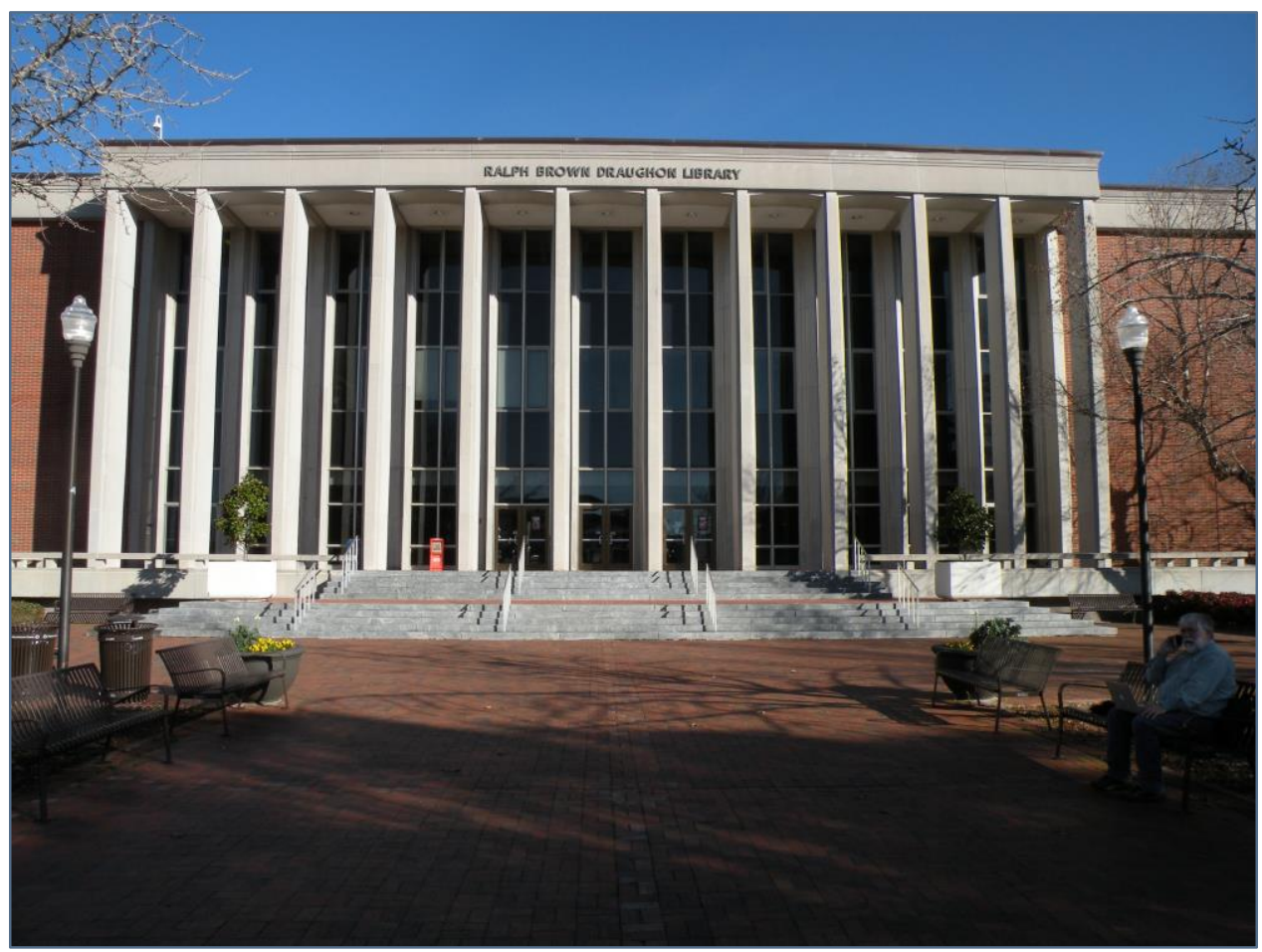

Draughon Library, before renovations. Photo by Jayson Hill

But how to design such spaces? What should they be like? To answer these questions, library leaders created a project team and asked Ithaka $\mathrm{S}+\mathrm{R}$ to help the team conduct studies with faculty members and students to understand faculty expectations, in-class student practices, and out-of-class practices and corresponding resource, space, and service needs.

In this report, we review the methods we used, discuss the findings, and share the implementation ideas developed by the project team with Ithaka S+R's support. We also provide an update on the construction and renovation project, which will be completed in 2017. 


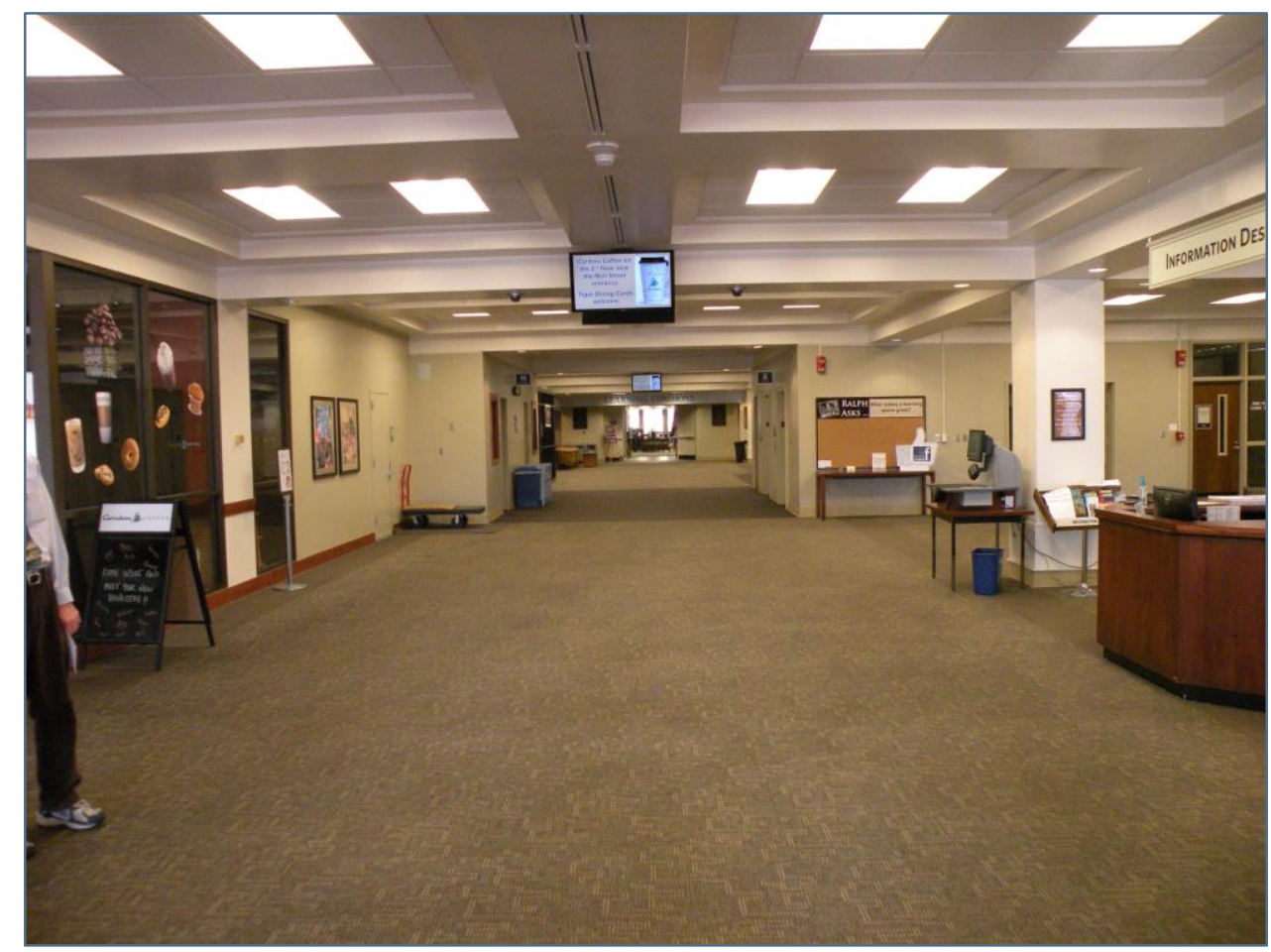

Draughon Library, before renovations. Photo by Jayson Hill

\section{Planning}

In early 2015, Auburn University decided to embark on a project to re-imagine the entry areas of Draughon Library, using participatory design techniques. The project launched in July, 2015, with the creation of research protocols, the naming of a project team, and the submission of the project to Auburn University's Institutional Review Board (IRB). The project's sponsor was Bonnie MacEwan, dean of libraries, and the project's leader was Marcia Boosinger, associate dean. Team members included Adelia Grabowsky, Ashley Goerke, Catherine Price, Cayce Van Horn, Chris Mixon, Cory Latham, Denise Baker, Greg Schmidt, Juliet Rumble, and Kasia Leousis. ${ }^{2}$ The Ithaka S+R team included Nancy Fried Foster and Lise McKean, and Danielle Cooper, who assisted with data analysis.

The project was cleared by the IRB and work began in September 2015 with the training of the project team, followed immediately by an initial four days of data gathering. The Auburn team completed data gathering in October, Ithaka S+R analyzed the data in November, and a second workshop was held in December 2015 to interpret the analyzed data and develop requirements and design concepts.

\footnotetext{
${ }^{2}$ We also thank two Auburn students for their valuable assistance to this team.
} 


\section{Approach}

We sought in this project to identify key faculty expectations and student activities associated with undergraduate classwork, with an emphasis on requirements related to courses taught in EASL rooms. We used a participatory design approach, engaging the people who will use the space in the design process in order to capture their expert knowledge of their own work practices and needs. We began the study by interviewing faculty members in order to understand their teaching practices and what they expect of their students. We also included librarians because they have expert knowledge of students across disciplines, years, and programs.

Work-practice study refers to a focus on the very activities in which people engage when they accomplish their work. In the case of undergraduates, work practices include all that they do to complete their assignments, prepare for classes and exams, work on projects, and so on. Undergraduates may also do some work of growing up and learning the ropes, developing a greater understanding of their field and scholarship in general, and figuring out what interests them and how they plan to move forward in life. 3

All of these practices may be intertwined and this may increase the importance of providing space for them that is more than utilitarian: the space will need to support their hearts and bodies as well as their minds.

\section{Methods}

The project utilized four information-gathering methods, benefitting from work done previously at Purdue University to design the Active Learning Center. 4

\section{Faculty expectation interviews}

We conducted conversations with teaching faculty in four different departments to gain an understanding of the work activities they believe are required for student success in their classes. The faculty members with whom we spoke use active learning approaches and have taught in EASL classrooms. We interviewed a total of 12 faculty members in science, social science, and humanities disciplines, including four in biology, three in

\footnotetext{
${ }^{3}$ Marcy Strong, Kenn Harper, and Mari Tsuchiya, "Learning the Ropes," in Studying Students: A Second Look, ed. Nancy Fried Foster (Chicago, IL: Association of College \& Research Libraries, 2013), pp. 45-61.

${ }^{4}$ Nancy Fried Foster et al., "Participatory Design of Purdue University's Active Learning Center Final Report," Libraries Reports (West Lafayette, Ind.: Purdue University, May 2013), http://docs.lib.purdue.edu/libreports/1.
} 
physics, three in English, and two in public relations and communication. The interviews included open-ended questions related to curriculum, course assignments, expectations regarding student preparation and participation, and resources and physical spaces that would support and facilitate the work of the class when students are not in the class.

\section{Design workshops}

We held several workshops in which 20 faculty members, 20 library staff members, and 20 undergraduates used art materials to depict an ideal non-classroom space after being prompted with a scenario.

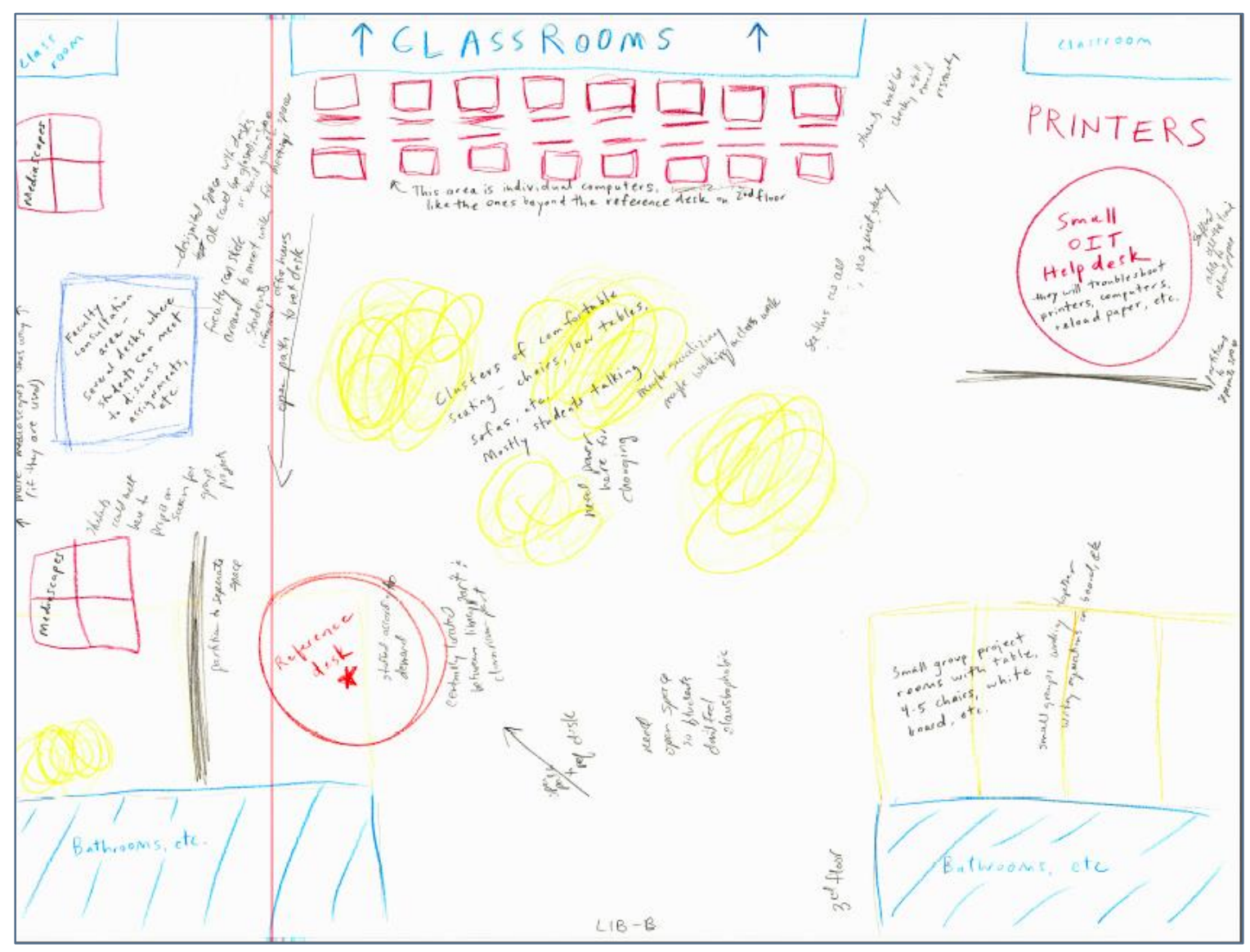

Drawing from design workshop

Facilitators debriefed each participant and made detailed notes about the activities depicted. In each category, we used two scenarios: a space adjacent to an EASL classroom and a space in the library not adjacent to a classroom. There was no discernable difference between drawings responding to the two different scenarios. 


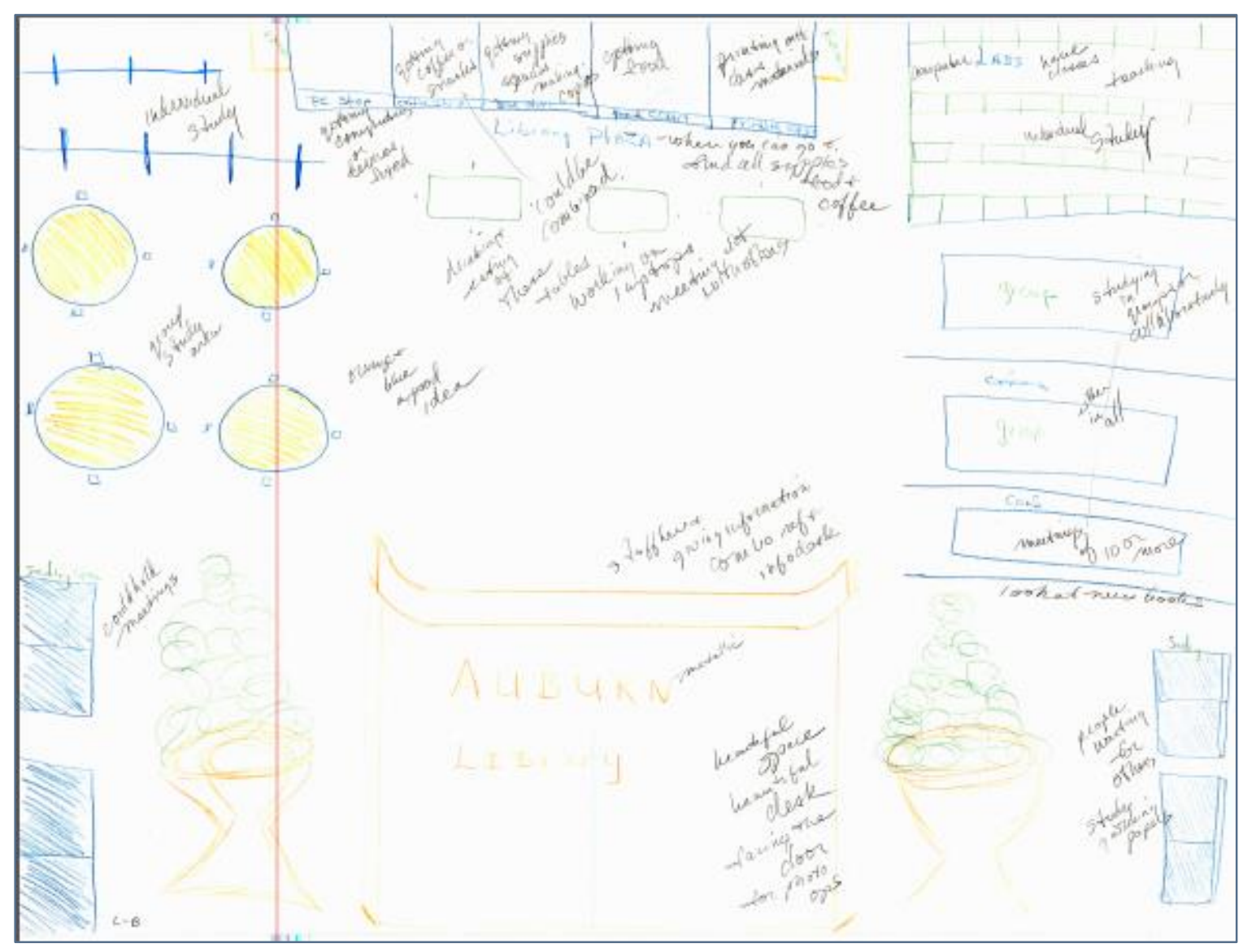

Drawing from design workshop

\section{Student snapshot interviews}

We recruited students at various locations around campus for ten-minute interviews about their most recent out-of-class schoolwork sessions. Students were asked to remember the last time they performed work for class outside of the classroom and then were asked a series of 13 questions designed to capture a picture of that effort. Students were asked to report on the time engaged in academic work, the type of work performed, their locations, their environment, and the obstacles to success they might have encountered. The 60 snapshot interviews covered both individual and group work.

\section{Reply cards}

On the team's behalf, the student member of the team distributed color-coded survey cards in preselected areas of the library to collect information about the ways in which students currently make use of the library. The areas selected for inclusion were carrels, computer workstations, tables, sofas/easy chairs, and study rooms/alcoves. We received and analyzed 141 cards. 


\section{Findings}

In this section, we organize findings into categories that cut across methods and data sources. Our four categories are:

1. Information about active-learning classes derived from faculty interviews

2. Major findings about student work practices gleaned from analyses of reply cards and snapshot interviews

3. A summary of expected student work practices drawn from faculty and student interviews

4. Major themes related to ideal non-classroom spaces as described in faculty interviews and depicted in workshop drawings

\section{Unique characteristics of active-learning classes}

The characteristics of active learning according to our 12 faculty respondents constitute the context for information about the reported and expected student practices discussed in the following sections. This is because course instructors set the standards, communicate expected work habits (e.g., study and time management skills), and ultimately assign the grades. When students engage in academic work outside of the classroom, their professors' expectations and directions guide them. This has implications for space design insofar as students will perform best, by definition, when they are able to meet or exceed the explicit and implicit standards set by the faculty.

According to our interviews with faculty members, active learning classes at Auburn University entail less lecturing, more circulation around class to help students, and greater use of video, PowerPoints, and other media. Additionally, these classes feature more discussion, especially in small groups, as well as experimentation and activities for exploring and applying concepts. In general, instructors using EASL facilities divide their students into groups of three or four to engage in project work and discussion, bringing the groups back together to share with the whole class. Instructors who have taught the same class in traditional and "active learning" sections report that there is greater use of technology in the latter, including clickers, iPads, phones, laptops, whiteboards and glass boards, and online testing platforms. These courses use the Canvas course management system extensively, and reliance on the Internet is universal.

The faculty members we interviewed expect students to take responsibility for preparing themselves for class before arriving in the classroom and to develop good study and time management skills, that is, to complete all reading and assigned work on time. They believe the interactive nature of in-class work increases motivation, partially through the potential for embarrassment given the frequency with which students must speak up and 
share their work in class. Instructors also expect students to take all assigned online exams. Students are expected to interact with each other and help each other through peer teaching or peer assessment. They are also expected to be genuinely motivated to do well and especially to learn the material and the key concepts. Faculty members hope that active learning will support the development of thinking skills and enable students to build knowledge throughout the course so that they retain what they have learned. They say that the very best students distinguish themselves by doing original, creative work.

Beyond these expectations and requirements, faculty members shared with us additional important perspectives on active learning. In many of our interviews we heard faculty members say that college is different and harder than high school and that it is extremely challenging for some students to make the transition and take responsibility for their own education. This point was iterated by many of the librarians with whom we spoke, who see that some students seek active learning and other educational opportunities while others avoid the challenges and demands of the new pedagogy.

We were able to compare transcript data from interviews with faculty members in physics, biology, and English. Similarities, which outweighed differences, included the emphasis on before-class preparation, continuous learning and concept development, group work and peer feedback, and less lecturing with more use of online video and other self-use resources. Differences included a greater emphasis in biology classes on being present in the class to demonstrate learning and on continuing group work outside of class; more emphasis in English on being together in class but working alone outside of class; and more emphasis in physics on creative, exploratory, and playful activities.

\section{Reported student practices}

In this section, we abstract information about students' academic work practices from their own reports, provided on reply cards and in face-to-face snapshot interviews.

Frequency and length of sessions

Finding: Students engage in academic course work outside the classroom on a very frequent basis

Over 93 percent of interview respondents reported that they conducted course work outside the classroom on the same or previous day as the snapshot interview.

Finding: Students who use the library are frequent visitors 
Based on the responses to the reply cards distributed in the library, we found that half of the students had used the library one day prior to completing the card, while a little over a third of students noted that they had used the library in the prior week. One in ten respondents reported that this was their first time in the library, but note that reply cards were distributed at the beginning of the fall semester.

\section{Finding: Students study on average for an hour or two}

According to snapshot interview responses, students spend 2.3 hours on average on course work outside the classroom. Students engaged in general schoolwork or writing a paper or essay appear to work over longer time periods than students engaged in other activities, such as research or studio work.

Students responding to reply cards in the library had been there for an average of 84 minutes when we interrupted them.

Sitting and working with others

Finding: Students like to sit with people they know in the library although in other locations they tend to be alone

By a six-to-four ratio, students responding to snapshot interviews reported working alone. Those studying for tests seemed to have the strongest preference for working alone. Students at home or in the dorm seemed more likely to be alone than those in the library who tend to work with others by just less than a two-to-one margin. Of those who sat together, only about 40 percent were working on the same thing.

Individuals sitting with others tend to choose a location where furniture and equipment support their work, while those working alone want a place where they can focus. Both those working alone and those sitting with others want a quiet place, but quiet is a more important factor for those working alone.

Reply card respondents in the library reported sitting with people they knew by a threeto-two ratio, but a smaller number, just under half, reported conducting academic work with another person. An even smaller proportion, less then one in ten, had engaged in a group project in the library at all that day.

Where they work

Finding: Students work on campus, mainly in the library, or at home or in the dorm 
Forty-eight percent of the snapshot interview respondents conducted their coursework on campus, compared to 43 percent who worked at home or in the dorm. Of those on campus, 30 percent (the largest share) had been in the library.

Why they work there

Finding: Most students seek environments that enhance their ability to do academic work

The largest group of responding students reported choosing locations for their academic affordances, resources, and availability of help (over 40 percent). Others simply chose a convenient location (just over 30 percent; this includes many who stayed at home or in the dorm). Smaller numbers choose locations that are comfortable (about 8 percent) or that are regularly used by members of the same sorority or fraternity.

Students working in non-library locations on campus seem to do so mainly because the location is convenient or because the resources they need are there. Those working at home or in the dorm do so mainly for convenience but also for academic affordance. By contrast, those working in the library do so very clearly for academic affordance.

Finding: Students seek spaces that support academic tasks by ensuring some combination of quiet, privacy, comfort, and furnishings that are appropriate for particular tasks

Almost two-thirds of the reply card respondents working in the library do so mainly because it helps them accomplish their academic work by providing quiet spaces, appropriate furnishings and equipment, and other supports for focus and concentration. Other reasons include convenience or habit (about one in five) and the ability to interact with others in the library (about one in ten).

Finding: Students who work in the library give evidence of a strong attachment to it as a place for academic tasks

Students surveyed in the library express little desire to work elsewhere. Almost eight in ten would move to another part of the library if they had to leave the seat they occupied when they were handed the reply card. About 14 percent would go home or to the dorm, or to another campus location. The remainder, about 11 percent, would go to scattered locations, many attempting to reproduce the affordances of the library space.

Finding: Student work sessions are mainly devoted to learning course material, completing assignments, or studying for tests 
Students report that in the most recent study session they worked on mixed or general tasks revolving around learning course material and completing assignments (almost half) or studied for a test (a bit over a quarter). The remainder wrote papers, read, did studio work, conducted research, or did other activities.

Finding: Students in library spaces overwhelmingly work on academic tasks

Nine out of ten students responding to reply cards in the library reported that they were doing academic work or closely related tasks such as checking due dates or setting up a computer. One in twenty respondents in the library reported they were relaxing, socializing, or engaging in another activity that was not related to academic work.

Among those who seemed to be doing general academic work, almost half were engaged in "studying," a mixed category related mainly to reviewing course material but also including studying for a test. Just under a quarter of our respondents told us that they were working on a project or homework assignment.

\section{Expected student practices}

In this section, we draw from information provided by faculty members regarding their expectations of what students must do outside of class in order to do well in the course. We add insights from students' own comments about the difficulties they encounter when doing classwork outside of class and what would help them do better.

\section{Student point of view}

Finding: Three in five students find it hard to get their work done

Students report difficulty doing their schoolwork due to external distractions such as noise and movement by people nearby (about 25 percent) or internal distractions such as worry (about 8 percent). Some students find the work itself to be so hard as to present difficulty (about 8 percent). Some students report being tired or unprepared or not having enough time to complete their work. Interestingly, almost 8 percent complain of a lack of resources.

Finding: Students desire improvements in their working environments.

Three in five students reported that they would have done better under better study conditions, such as quiet or isolation, or with some form of help, such as a study partner or better instruction. A little over ten percent would like better infrastructure or 
resources; the library may be a good place in which to address these types of need. The data suggest that students see isolation as an antidote to distraction.

Faculty expectations of students outside of class

Finding: Instructional faculty expect students to devote time outside of class to prepare and complete assignments, papers, and projects, learn course concepts and material, and prepare for and take examinations

Outside of the active-learning classroom, instructors expect that students will read texts and view videos and other course resources; complete homework assignments, some of it online; write essays, reports, and research papers; complete long-term projects; engage in experimental work in labs or with ordinary materials; and conduct research using mainly online materials. Further, the expectation is that students may work alone or in groups, as required by the particular assignment, and that they may use a variety of applications and media (PowerPoint, video, etc.).

Instructors also expect that students will study and learn course material whether alone or in assigned or voluntary groups; that they will teach and learn from each other; and that they will attend office hours or meet with the instructor. Students are also expected to seek help, when needed. Help is available from the university's Writing Center and from the Office of Academic Support's Supplemental Instruction program, online help and study aids, peers, and tutors.

Students are expected to use a variety of information resources, including general and special collections in the library and purchased, rented, or borrowed textbooks in print or online. Students are also expected to use a number of learning technologies. They use the course management system, Canvas, to get the syllabus, readings, and other information, communicate with the instructor and peers, and post assignments. They use communication and collaboration platforms such as email, GroupMe, Google Drive, Facebook groups, and Skype. And they use a wide range of applications and devices, including laptops, public workstations, online texts, homework platforms, and testing platforms. Instructors also require that students engage in assessment activities, including self, peer, and instructor assessment that entail feedback mechanisms and online exams and quizzes.

Finding: Instructional faculty expect that students will work in groups in the classroom but have mixed opinions with regard to group work outside of the classroom

While some faculty respondents indicated an expectation that students would take it upon themselves to meet with others in voluntary or assigned groups to study, learn 
course concepts and material, and complete projects, others stated a belief that such an expectation was unreasonable. We did not discern a clear trend.

\section{Envisioned space}

Asking faculty members, librarians and library staff, and students to envision an ideal space for students to work on course-related tasks outside of the classroom yielded an abundance of data relevant to specifying the space's requirements. These data pertain to the space in terms of its physical characteristics as well as the activities people engage in when in the area and the technological and other resources necessary to support students' work activities.

The data sources for the findings presented in this section are the set of 60 workshop drawings and the set of 12 faculty expectation interviews.

Twenty faculty members, 20 librarians and library staff, and 20 students created drawings of library space in design workshops and were then debriefed by project team members. The contents of faculty and librarian drawings align more closely with each other than with student drawings. The student drawings include fewer features, and features that are more oriented to individual experiences than to general needs. Conversely, librarian and faculty drawings provide a larger view of needs across a range of students and courses and the features that would be necessary to meet them.

Faculty expectation interviews were conducted with faculty members in science, social science, and humanities disciplines. At the end of the interview, faculty were asked to "imagine for a moment an ideal place where students could do their work for you outside of class time and outside of the classroom. What would this place be like?" Interviewers probed for information about the look, feel, and sounds of this ideal space. The themes discussed here are also based on data from interview questions pertaining to the classwork that needs to be accomplished outside of the classroom, the resources needed to complete classwork, and the types of activities related to group work.

With regard to envisioned space, we found similarities among the biology and physics interviews and some contrasts to the English interviews. For respondents teaching biology, the ideal workspace for students outside of class would resemble the EASL classroom in terms of technology, glass boards, moveable furniture, and access to instructional support but with added amenities. Respondents teaching English indicated that reading and writing constitute the major out-of-class activities. Out of class, students are asked to work individually and would be expected to need a space with varied seating (for individuals and groups) and an active but non-disruptive atmosphere-that is, a place to concentrate, read, and write. 


\section{Envisioned spaces: Key themes}

Envisioned spaces will serve needs that are diverse and dynamic; these needs are driven by different disciplinary and pedagogic factors as well as academic level and work habits. Also, during any single library session, a student may have to work on multiple tasks, either sequentially or simultaneously, each of which may benefit from different types of peer presence and involvement, access to learning resources, technology, and instructional supports.

The themes related to envisioned spaces are:

- Supporting classwork

- Enabling a variety of work configurations

- Allowing students to meet physical needs and achieve mental readiness for work

\section{Classwork supports}

Finding: The envisioned spaces support performance of a wide range of classwork tasks

The overlap between classwork performed in and out of EASL rooms gives rise to considerable similarities between the envisioned spaces and EASL rooms.

Classwork tasks that respondents indicate students need to perform outside of the classroom include:

- Reading

- Conducting library-based research

- Completing written assignments

- Engaging in online self-assessments (quizzes and exams)

- Engaging in peer and instructor assessments

- Completing semester-long projects

- Making and viewing PowerPoint presentations

- Making and viewing videos

- Doing group projects 
- Getting help, including teaching each other and learning course concepts and material together

Finding: The envisioned spaces provide a robust infrastructure for the use of apps and devices as well as specialized technologies required for classwork

Students need to perform tasks outside of the classroom that require access to learning resources and technology, including assistance in using them. They need access to computers, including Macs and PCs provided for them in the space, and their own laptops, phones, tablets, and other devices. They also need to use specialized tools and equipment, including graphics software and tools for media production, scanning, and printing.

Learning resources and technology in the envisioned space will allow students to:

- Use computers, including Apple computers

- Gain access to the Internet (Wi-Fi saturation)

- Make and watch presentations and videos

- Print documents

- Communicate via Canvas and email with instructors and peers

- Use communication platforms including GroupMe, Google Drive, Facebook groups, and Skype

- Charge electronic devices

- Write and draw on glass boards

- Project and view video, slides, and other material on large screens

\section{Work configurations}

Finding: The envisioned spaces support different types of interaction among students and between students and faculty and other instructional support (librarians, technology support, tutors)

Data from faculty, librarians and library staff, and students indicate that the envisioned space will need to be flexible in order to accommodate meeting and working together in small, medium, and large groups. Since the space will be close to classrooms, it will serve as a transitional space for students and faculty to meet formally and informally before and after classes. The view that the space would be used for informal meetings prior to class and for continuing discussion after class recurred across interviews and drawings. 
Students' work habits and types of tasks influence the extent to which they want to work with or near friends and peers. Group projects or collaboration on problem sets and other assignments may require workspace with computers, projectors, and white/glass boards. The collaborative work area is envisioned as having the low buzz of people working quietly at moveable tables that can be configured as needed. This core area could be surrounded by seating areas suitable for more informal meetings and discussion among small groups. This area in turn would buffer noise from the area with people working in groups.

Suggestions were also made about providing space for students to meet individually with faculty, graduate teaching assistants, and librarians, and to obtain assistance from the university's writing and academic support services.

Finding: The envisioned spaces provide areas of quiet for students to work alone and without social, visual, or auditory distractions

Students like to work with their friends or other students around them when it helps them stay on task. They also know that this proximity can be a source of distraction. Some students prefer to work in solitude and quiet, away from people they know and noisier peers. Suggestions for the quiet area include providing background sound, such as that of birdsong and the ocean, or installing a waterfall.

\section{Care of self and state of mind}

Finding: The envisioned spaces provide the amenities students need in order to focus on their work and persist in it

Data show that the envisioned space addresses the physical needs of its occupants. This includes access to food and drink as well as surfaces that are large enough for students to spread out textbooks, laptops, notebooks, and other work materials. The space should have furniture that allows easy reconfiguration for different size groups. Comfortable furniture is also envisioned for weary students seeking a rest.

Finding: The envisioned spaces have aesthetic qualities that contribute to students' productive and creative performance of their work

The data are mixed about aesthetic preferences and not every respondent paid attention to aesthetics. However, those who did gave particular attention to qualities of light, color, and spaciousness. Some also suggested installing paintings and sculpture as a spur for creativity. 
Windows were envisioned for the space to provide natural light as well as a view of trees, the sky, and nature more generally. In addition to natural light, comments about the quality of artificial light stated a range of preferences: bright, not too bright, and no glare.

No matter how the space was described from an aesthetic point of view, the data show that it is envisioned as providing an atmosphere that fosters calm and collegiality, creativity and diligence.

\section{Results: Requirements}

Our studies and subsequent analyses enabled us to develop a set of requirements for space to enable students in EASL classes to complete their classwork outside of class. These requirements can be read as a set of affordances. That is, in order for the space to be successful, we have concluded that it must afford a number of different activities or academic work practices. The following list is based on those activities and practices.

- Provide for small-, medium-, and large-group work as well as for students working by themselves, noting that many students want to work "alone together" (that is, work quietly on their own assignments while they are next to friends)

- To the extent possible, ensure that students can work in quiet, semi-quiet, or noisy environments depending upon their needs

- Provide space that is reconfigurable so students can readjust the space over time for large or small group work or individual work

- Provide environments and furnishings that are varied so that within the overall space students can conduct such different classwork activities as:

- Reading

- Conducting library-based research

- Completing written assignments

- Engaging in online self-assessments (quizzes and exams)

- Studying for exams

- Engaging in peer and instructor assessments

- Completing semester-long projects

- Making and viewing PowerPoint presentations

- Making and viewing videos

- Doing group projects

- Getting help, including teaching each other and learning course concepts and material together 
- To the extent possible, provide large, unbroken work surfaces so students can spread out their materials individually or share materials in pairs or groups

- Provide technologies that support shared learning and viewing, such as projectors, flatscreens, white/glass boards, or the next technology that serves the this purpose

- Ensure the space has a robust infrastructure, particularly outlets and Wi-Fi, to enable the use of a multitude of devices

- Enable both the provision of public workstations (Mac and PC) and the use of own laptops, phones, tablets, and so on

- Integrate specialized technology into the space, such as computers with graphics software and media production capabilities, scanners, printers, and so on

- Enable students to get technical, academic, and library support by providing for some combination of service points (such as information desks) and support for roving service providers (such as a paging capability)

- Accommodate students who stay for the average of one or two hours but as much as eight hours per session and who will need food, water, rest, and breaks

- Attend to a subtle need for an environment that calms and soothes yet energizes and inspires

In particular, in areas directly adjacent to EASL or active-learning classrooms:

- Favor group-work configurations so that students who begin group work within the classroom can continue it when they are dismissed to the adjacent space

- Provide for transition in and out of class, informal meeting, and last-minute prep

- Consider providing space for open or semi-private meetings of faculty members and other instructors with their students or with librarians 


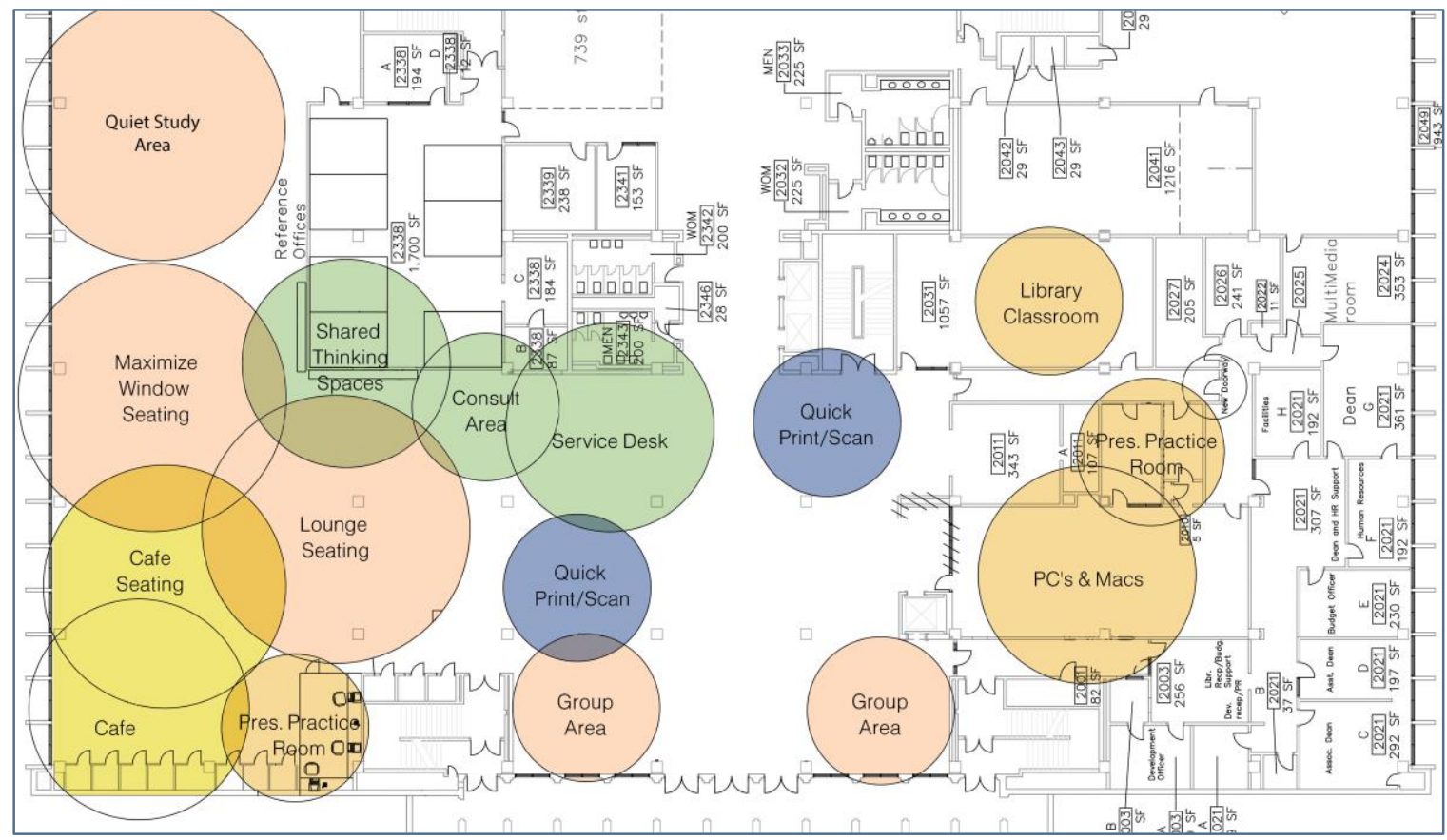

Initial design based on project findings. Image by Williams Blackstock Architects

\section{Results: Implementation}

Library leaders at Auburn University worked with project architects to ensure that important student, faculty, and librarian work practices would be afforded in the new spaces. Through a series of meetings among architects, designers, and library leaders, they discussed the findings of the study done with Ithaka $\mathrm{S}+\mathrm{R}$ and information collected on service points collected by library staff. Later in the process, they reviewed plans together. 

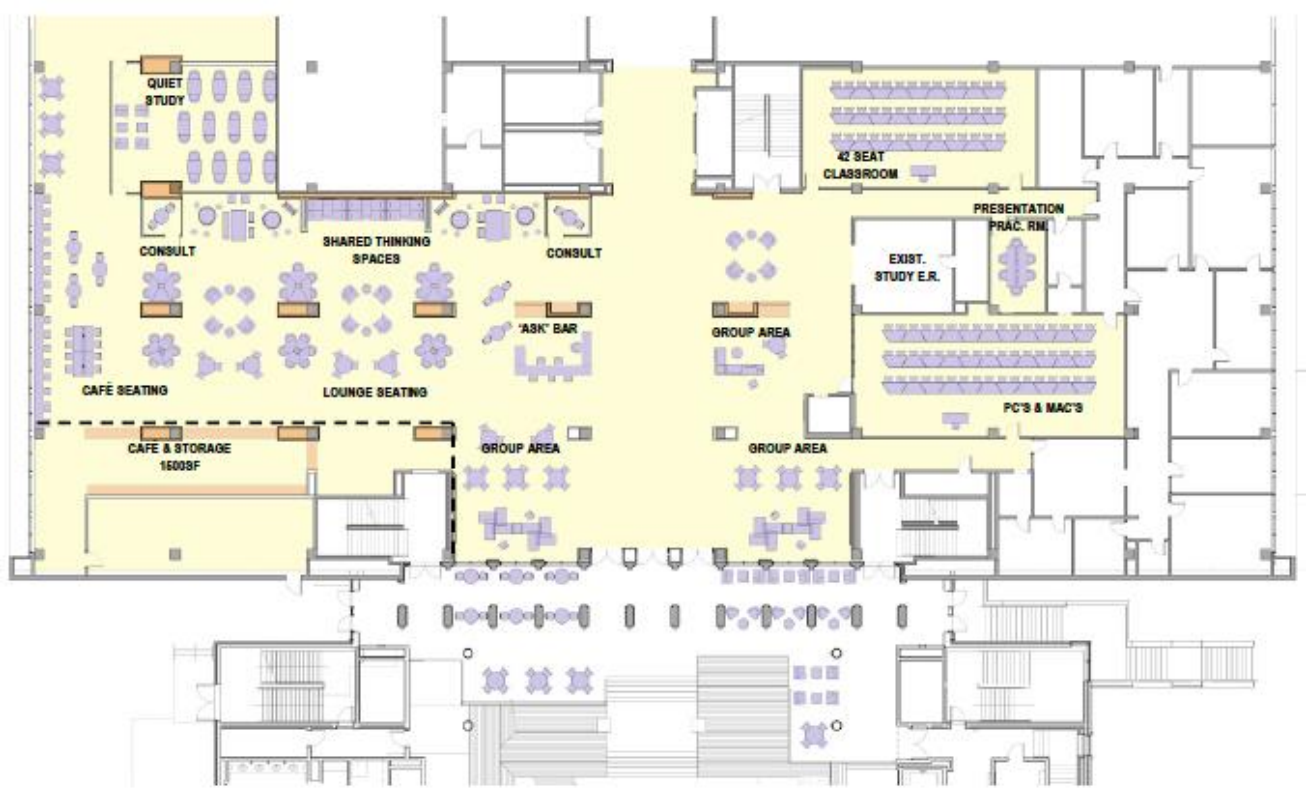

Schematic Design - Floor Plan

Floor plan by Williams Blackstock Architects

Librarians were able to plan a general layout based on the results of the study reported here, paying particular attention to the various uses and types of work that would be conducted in the library by students taking EASL classes. 


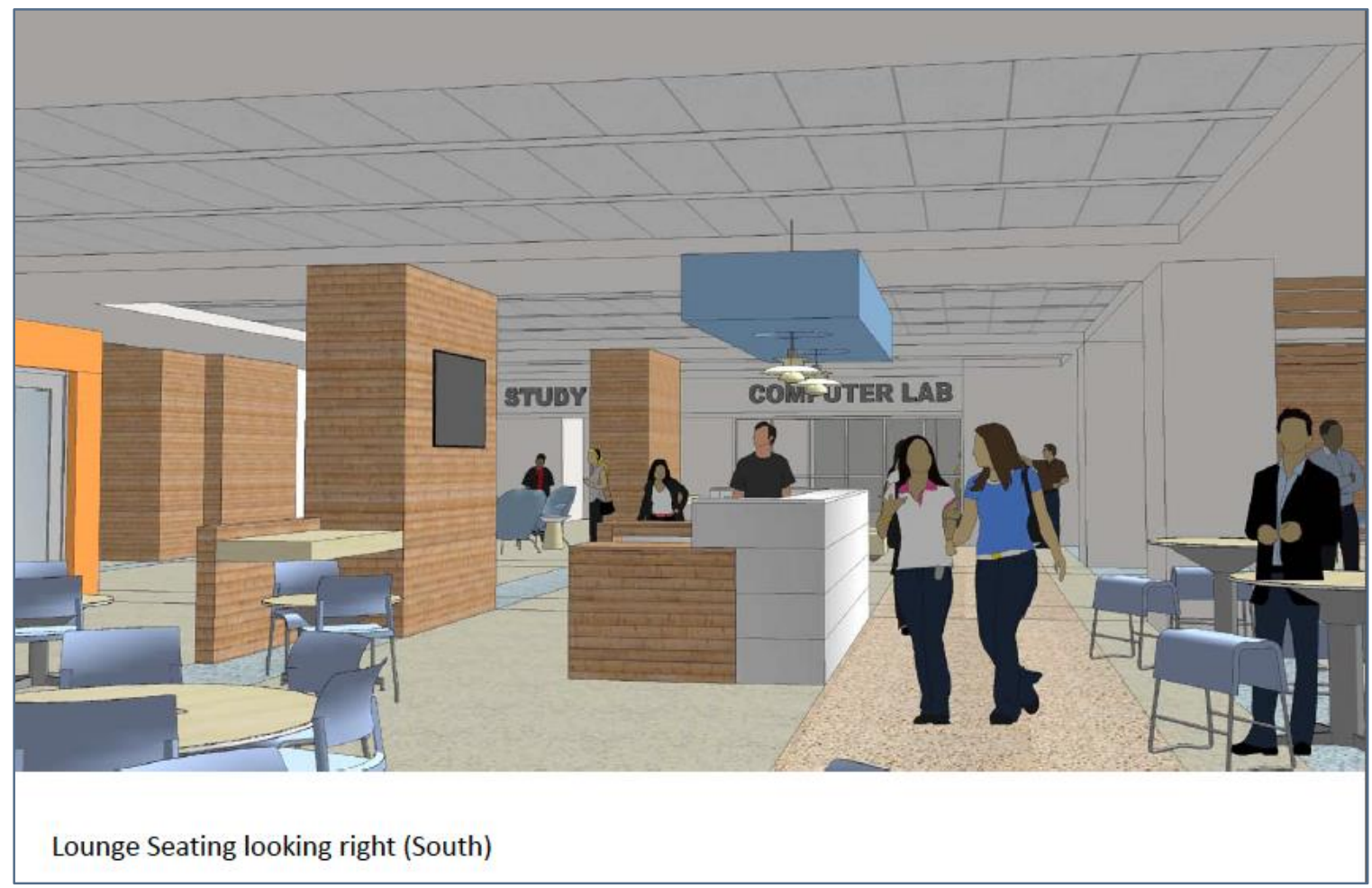

Interior image by Williams Blackstock Architects

As of publication of this report, the former grand entrance to the library has been converted into an emergency exit and a side door is serving as the main entrance. Books, equipment, furniture, and sundry materials in the project area have been shifted to other parts of the building and construction is scheduled to begin during the winter break following the Fall 2016 semester. The former main entrance will reopen next year and it will be an internal entrance to the library from within the new atrium that connects the library to the classroom building, which is now under construction. Both the new classroom building and the renovated library spaces will be open by the first day of classes in fall semester of 2017. 


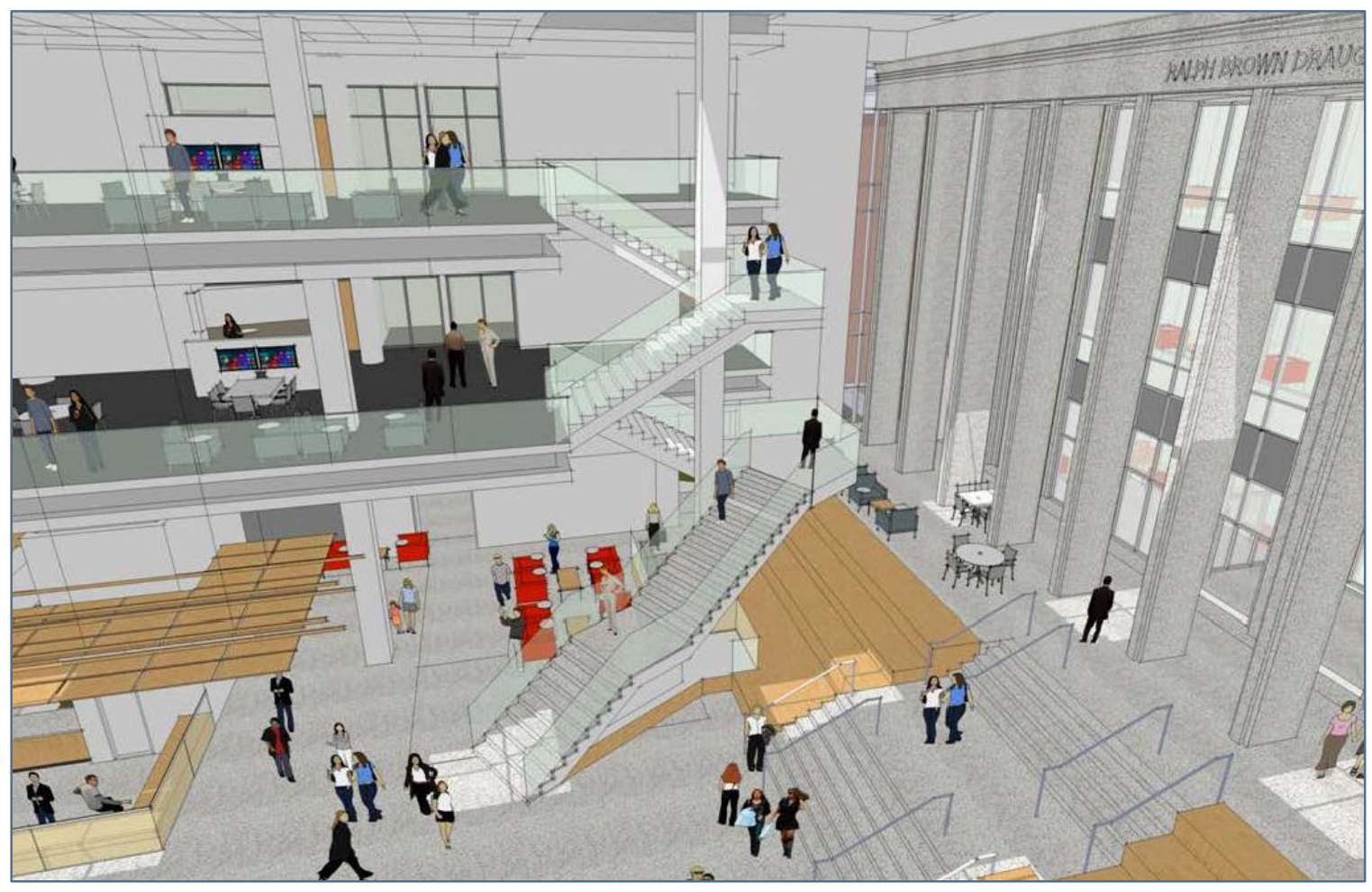

Interior image by Williams Blackstock Architects 